\title{
Creating a Current Atlas for the Port of Zeebrugge
}

Jeroen AARDOOM, the Netherlands

Frans CLAEYS, Belgium

Hans POPPE, Belgium

Shauna NI FHLAITHEARTA, the Netherlands

Pim VAN SANTEN, the Netherlands

Topic J: Accurate hydrodynamics

\section{INTRODUCTION}

Current atlases are used in many ports around the world to assist shipping and increase safety on approach and within the port. For this reason the coast division of the Flemish government launched a tender to compile a new atlas for the port of Zeebrugge, which was appointed to Eurosense Planning and Engineering NV and subcontractor Aqua Vision BV (Figure 1). The current pattern in the outer port of Zeebrugge is strongly influenced by the tidal cycle. As such, an accurate and detailed current atlas is of vital importance for the safe and effective navigation of shipping into the Port of Zeebrugge.

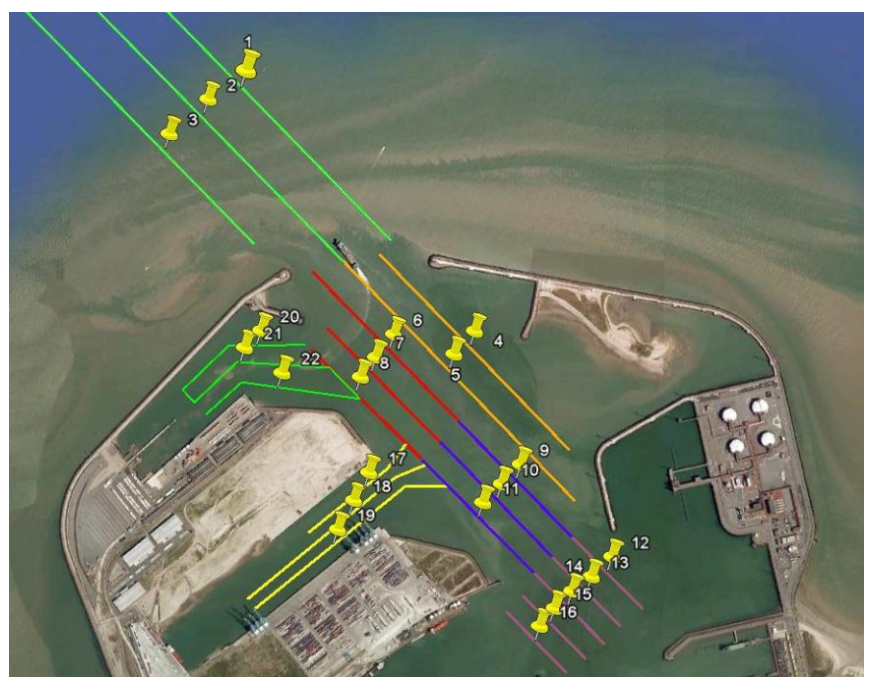

Figure 1: The outer Port of Zeebrugge with the survey zones marked by coloured stripes. Adapted from Verwerkingsrapport Stroming meetcampagnes Zeebrugge [2011].

The current atlas was constructed for the outer port during spring, neap and average tides. To achieve this, a strict surveying scheme was created using multiple vessels surveying simultaneously (Figure 2). All vessels were mounted with an Acoustic Doppler Current Profilers (ADCPs), which measured current speed and direction using broadband technology and bottom track functionality.

(a)

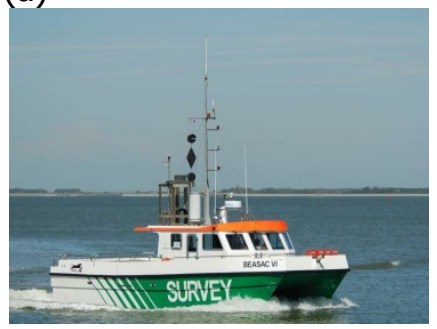

(b)



(c)



Figure 2: Survey vessels used for the ADCP measuring campaign, a) MS BEASAC VI, b) MS EB2, c) MS WALRUS. Adapted from Verwerkingsrapport Stroming meetcampagnes Zeebrugge [2011].

Low current speeds, a diffuse sediment layer and choppy wave conditions made measurements in the outer port of Zeebrugge a challenge. Furthermore, shipping activities in this busy port required survey 
vessels to veer off course, leading to gaps in the surveying scheme and a disruption to acoustic signals.

To solve these challenges, Aqua Vision BV developed two novel solutions for port based surveying. First, a new data processing approach optimized data quality by using a combination of bottom tracking and dGPS. In this way, an optimum current speed solution could be derived, ensuring accurate and precise current speed and direction data. Second, a central surveyor station was set up using a remote desktop connection to all survey vessels, in order to optimize real-time planning and anticipation of shipping activities.

\section{METHODS}

The port was split into several distinct zones (Figure 1). Three survey vessels were equipped with ADCPs (Teledyne RD Instruments) and deployed to simultaneously survey during spring tide, neap tide and average tide. For each tidal type, three boats surveyed all zones in two days of 13-hour measurements. Data acquisition and reprocessing were performed using the data acquisition software package ViSea-DAS (Aqua Vision BV), affording real-time synchronization between ADCP, GPS, gyro compass and motion sensor. Data quality control, presentation and current atlas generation was carried out using ViSea-DPS (Aqua Vision BV).

\section{RESULTS AND DISCUSSION}

A representation of the current patterns in the outer port of Zeebrugge during spring, neap and average tides was created to aid shipping and navigation in this busy port (Figure 3 ).

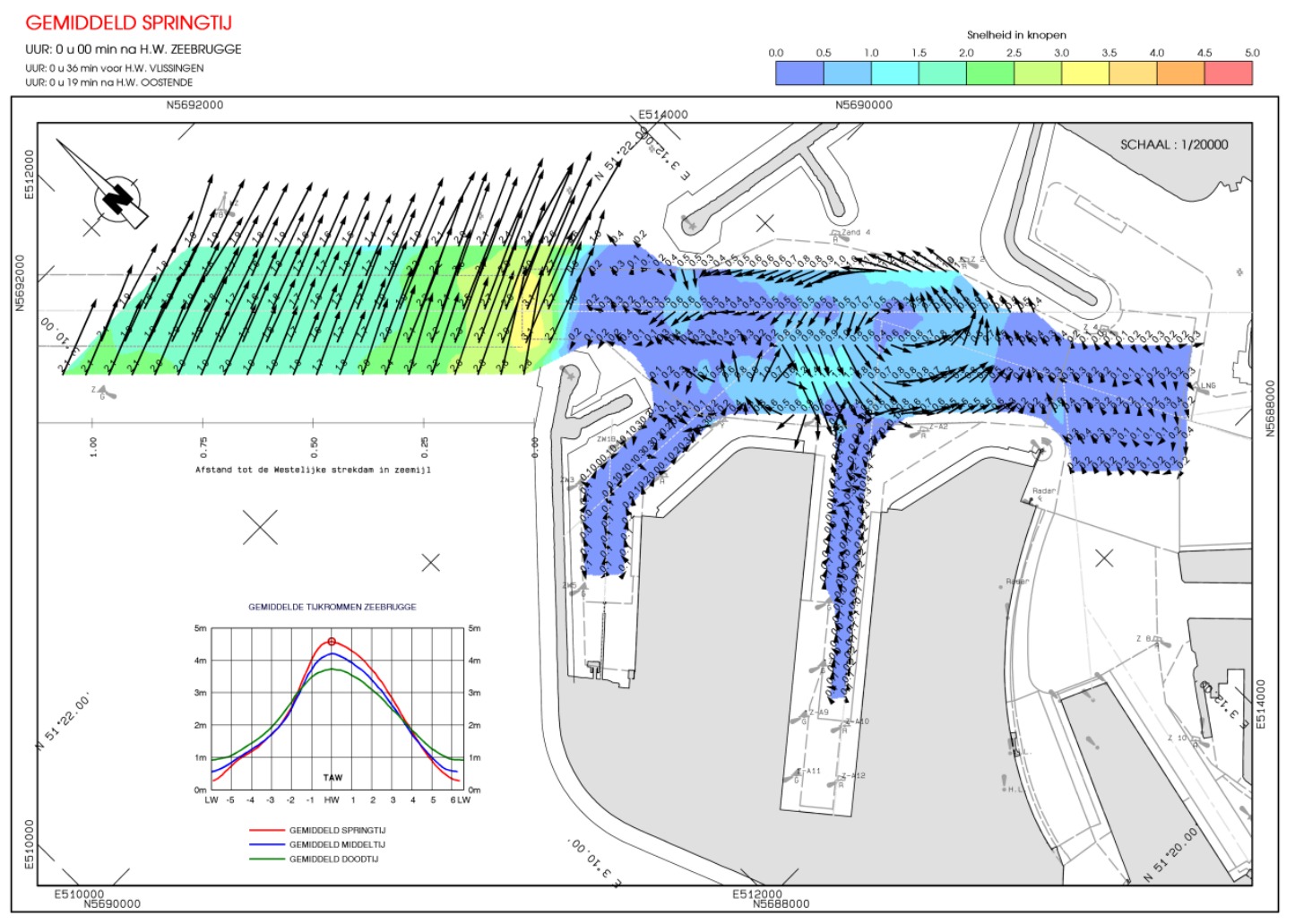

Figure 3: Current patterns during high spring tide. Adapted from Stroomatlas Haven van Zeebrugge [2011].

The series of current maps provide insight in the 3D current patterns in the outer port of Zeebrugge. The most striking current patterns were visible during the spring tide. In the initial phase of high tide 
the currents outside the port remain southbound. This reflects the inertia of the westwards flowing water mass. As such, water enters the port basin from the south side of the port entrance and current velocities at the entrance are relatively weak. Two hours before high tide, currents outside the port have turned and start filling both Zeebrugge port. This coincides with the onset of the steepest part of the water level curve, which cause steep spatial water level gradients between the sea and the port basin. This results in high current velocities throughout the port system. Water enters the port at the north-eastern side of the entrance and flows to the tip of the Leopold II-dam. This creates a jetlike system with the highest current velocities directed inward on this line. To the east and west, a return flow is created, causing a double eddy system in the outer port basin.

At the peak of high tide, the basin is completely filled, while currents are still strongly flowing northward at sea. The double eddy system however continues swirling inside the outer port basin. At this time, strong vertical shear also exists. An example can be found in the outer part of the port basin, just inside the port entrance, northeast of the Wielingendok (Figure 4). A seaward return flow is active near the water surface (Figure 4a) while water is flowing inward near the bottom (Figure 4a).

a)

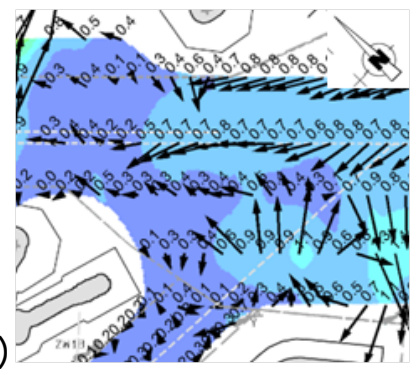

b)

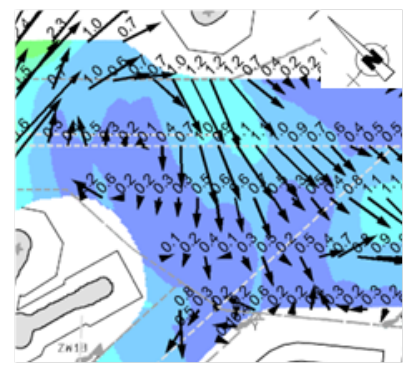

Figure 4. Current pattern at spring high tide just inside the port basin at (a) $2 \mathrm{~m}$ depth and (b) $16 \mathrm{~m}$ depth.

With the falling of the tide, the double eddy system is pushed seaward until it has vanished at 4 hours after high tide. From this time onward, water is steadily flowing out of the basin until low tide is reached. Current patterns at mean tide and neap tide are similar but with smaller current velocities.

The high accuracy of the measurements becomes evident when viewing the current pattern in the entrance of Wielingendok at $4 \mathrm{hr} 40$ before high tide (Figure 5). Although the current velocities are extremely low ( 0.1 knots on average), an eddy is clearly visible, having developed due to water entering at the south side of the Zeebrugge port entrance.

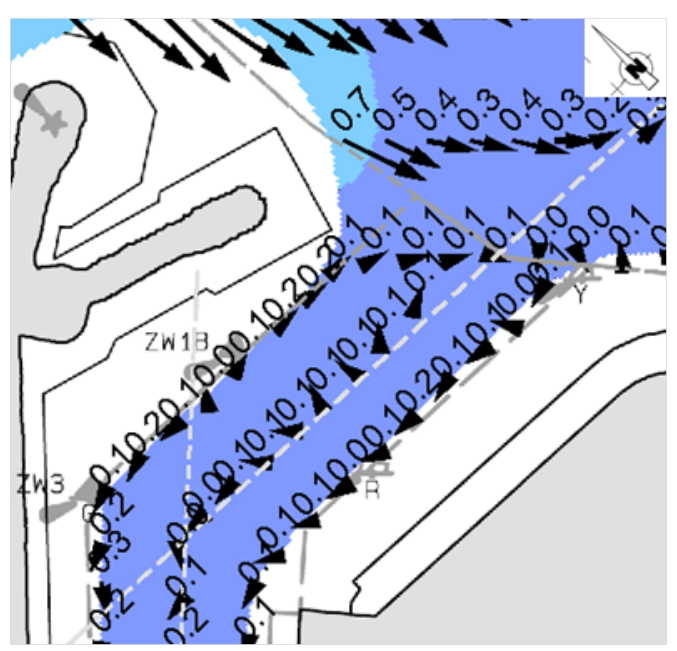

Figure 5: Current pattern at $4 \mathrm{hr} 40$ before spring high tide in the entrance of Wielingendok. Even though current velocities are small, a clearly visible eddy has accurately been mapped. 


\section{MOVING BED}

Low current speeds are inherent to port basin environments. Under such conditions the differential between current speed and vessel speed becomes a crucial factor in determining the precision of the data. During the data validation step the measured current speeds are corrected for vessel speed. In this case bottom tracking is always the preferred method due to its direct synchronization with the ADCP. However, local sediment dynamics can sometimes disrupt bottom track detection, either due to a moving bed or no bottom detection.

This was case in the Port of Zeebrugge, where the muddy seabed at times became too diffuse to detect the bottom. When this occurs, bottom tracking is no longer available and GPS has to be used, with a resulting decrease in measurement precision associated with synchronisation issues. This results in sub-optimal current speed data. A new current speed correction method was developed based on a combination of bottom track and GPS data.

Vessel speed is measured dually by Bottom Track and by RTK. The speed variations are combined by making use of a low and high pass algorithm, speed variations with a period $<10 \mathrm{~s}$ are taken from the bottom track and variations with a period $>10 \mathrm{~s}$ is taken from the RTK. This combination corrects for both moving bottom and ships movements. In the absence of a moving bottom the bottom track is used exclusively. In Figure 6a, the uncorrected current speed data is shown. After applying the highlow pass filter method, a clear improvement is seen in the data (Figure 6b).

(a)

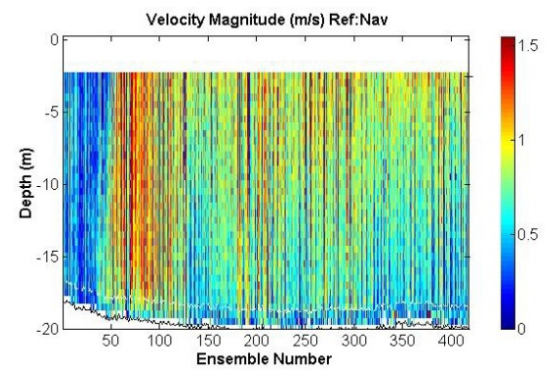

(b)



Figure 6: The application of a combined Bottom track/GPS correction for vessel speed, a) Velocity magnitude data before correction, b) Velocity magnitude data after correction. Adapted from Verwerkingsrapport Stroming meetcampagnes Zeebrugge [2011].

\section{CENTRAL SURVEYOR STATION}

Any approaching shipping in this busy port not only requires a survey vessel to veer off track, but can also disturbs the acoustic signal from the ADCP. Ultimately, this results in poorer data, time delays and gaps in survey coverage. One innovative solution was found in the creation of a central surveyor station in the Eurosense office in Zeebrugge (Figure 7). Here, a surveyor oversaw the survey activities of all three boats via a remote desktop connection with each onboard survey PC. At the same time, the surveyor kept a close eye on shipping activity via www.marinetraffic.com. In this way the central surveyor could anticipate impending survey disturbances and relay a new survey strategy to the onboard surveyor and skipper - resulting in increased safety and an optimised survey strategy.

With the advent of high speed mobile internet it is now possible to remotely operate survey software. With a central surveyor station, like that used in Zeebrugge, are we seeing the precursor of remote surveying? 




Figure 7: Central Surveyor Station in Eurosense office, Zeebrugge.

\section{CONCLUSION}

A current atlas has been created for the port of Zeebrugge during spring, neap and average tides to aid shipping navigating and safety on approach and within the outer port. This was achieved using 3 survey vessels measuring simultaneous over a 13 hour period, per tidal condition. Each survey vessel was mounted with an ADCP. Current patterns in the outer port show some interesting features, for example, a delayed response to rising tides, the creation of a double eddy system within the outer port and eddy systems even at very low current velocities. Due to local sedimentary conditions, a novel new method was used to correct the vessel speed data. To improve planning and anticipation during multi-vessel surveying a central surveyor station was set up using high speed mobile internet.

\section{BIOGRAPHIES}

Pim VAN SANTEN is now a researcher water systems at Waterschap Aa en Maas. He received his MSc in Physical Geography from Utrecht University, after which he spent several years as a researcher in sediment dynamics. At Aqua Vision BV he was involved in data analysis and processing.

Shauna NI FHLAITHEARTA, currently a data analyst at Aqua Vision BV, completed her BSc (Hons) in Earth Sciences at the National University of Ireland, Cork, and her MSc in Earth Systems Science at Wageningen University and Research Center. She then spend several years conducting research in marine biogeochemistry before joining Aqua Vision BV in 2010, where she is involved in data processing and communications.

Jeroen AARDOOM, a senior R\&D associate at Aqua Vision BV. He received his MSc in Physics from Utrecht University, specialisation computational science and physical oceanography. He worked at TNO Physics and Electronics Laboratory on the use of radar remote sensing data for underwater acoustics before he joined Aqua Vision. At Aqua Vision he develops hydrographic data acquisition software.

Frans CLAEYS, a senior project manager of Eurosense, received his Master of Science degree in electronics and control at the University of Louvain in 1982. After his military service he started with Eurosense in 1983 in the hydrographic department in Zeebrugge. He is experienced in accurate positioning, attitude determination, data acquisition and digital signal processing techniques.

Hans POPPE received his MSc in Physics at the University in Brussels in 1996 and his MSc in applied physics in 1999 at the University of Delft. From then on he started working for hydraulic and civil engineering consulting agencies, until the end of 2006 when he started to work as Project Engineer of Tide and Currents at the Coast Division of the Flemish government. In this job he is responsible for the various aspects involving tide and currents along the Flemish coast and on the Belgian continental shelf. 


\section{CONTACT DETAILS}

\section{Jeroen AARDOOM}

Aqua Vision - THE NETHERLANDS

Email: j.aardoom@aquavision.nl

Web site: www.aquavision.nl

\section{Frans CLAEYS}

Eurosense - BELGIUM

Email: info@eurosense.com

Web site: www.eurosense.com 